\title{
Estrategias socioeconómicas de inclusión de entidades locales dirigidas a personas mayores (mujeres), víctimas de desplazamiento forzado
}

\author{
Marta Sahagún-Navarro', Leandra Orozco-Tous², Martha Vergara-Garay², \\ Silvia García-Arias ${ }^{4}$
}

\section{Resumen}

El objetivo de este estudio es evaluar las estrategias socioeconómicas implementadas por entidades locales gubernamentales y no gubernamentales dirigidas a la mujer adulta mayor, víctima de desplazamiento forzado en el municipio de Sincelejo, Sucre, Colombia. Ello permite conocer la labor que el estado colombiano y las entidades no gubernamentales están llevando a cabo para mejorar la calidad de vida de esta población. Asimismo, permite evaluar cómo se ejecutan dichas estrategias de acuerdo a lo establecido por la legislación que respalda la protección y el restablecimiento de los derechos de las víctimas de desplazamiento forzado en Colombia. La metodología de esta investigación se desarrolló con el enfoque cualitativo, utilizando la entrevista semiestructurada conformada por veintisiete (27) preguntas, sometida previamente a los procesos de validación por juicio de expertos. Esta se aplicó a un total de cinco (5) entidades: cuatro (4) gubernamentales y uno (1) no gubernamental. El análisis de la información se realizó bajo el marco interpretativo de la teoría crítica. Las principales conclusiones

\footnotetext{
1 Corporación Universitaria del Caribe - CECAR (Colombia). Correo electrónico: martasn89@gmail.com. Magíster y Doctoranda en Atención Sociosanitaria a la Dependencia, Trabajadora Social, Docente-investigadora. Área de conocimiento: personas mayores, personas con diversidad funcional, población LGBTI, conflicto armado. Grupo de investigación: Dimensiones humanas. Línea: Vulnerabilidad y grupos poblacionales.

2 Corporación Universitaria del Caribe - CECAR (Colombia). Trabajadora Social egresada del programa de Trabajo Social.

3 Corporación Universitaria del Caribe - CECAR (Colombia). Trabajadora Social egresada del programa de Trabajo Social.

4 Corporación Universitaria del Caribe - CECAR (Colombia). Trabajadora Social egresada del programa de Trabajo Social.
} 
apuntan a que existen falencias en las políticas públicas de atención integral e inclusión a la población víctima, especialmente, a la mujer adulta mayor, en cuanto a las estrategias que deben implementar en función de lo plasmado en la conocida Ley de Víctimas y Restitución de Tierras (Ley 1448 de 2011).

Palabras clave: personas mayores, mujeres, desplazamiento forzado, estrategias socioeconómicas, entidades locales.

\section{INTRODUCCIÓN}

El desplazamiento forzado en Colombia ha sido una de las consecuencias más devastadoras que ha sufrido el país, a raíz de la violencia sociopolítica por la lucha del poder, lo que ha traído consigo la desintegración de núcleos familiares, produciendo el abandono de sus hogares y resguardándose en otros territorios del país. En este sentido, Mendoza (2012) destaca que el desplazamiento forzado y las migraciones regionales son una de las principales consecuencias de las guerras civiles y del enfrentamiento armado por el poder.

Colombia es el segundo país del mundo con mayor número de personas desplazadas, después de Sudán (Ibáñez y Velásquez, 2008; La Agencia de la ONU para los Refugiados, ACNUR, 2014). La Consultoría para los Derechos Humanos y el Desplazamiento (CODHES) arroja cifras alarmantes, pues "entre 1985 y 2008, la violencia obligó a más de cuatro millones de personas a dejar sus hogares por intimidación o violencia directa" (Mendoza, 2012: 170).

La región Caribe, por su posición geográfica, se convierte en un punto estratégico para la toma de los territorios que de él hacen parte, destacándose los Montes de María, ubicada entre los departamentos de Sucre y Bolívar, por el cultivo de ilícitos y el transporte de drogas.

De hecho, en los últimos veinte años esta región se ha configurado como una de las más violentas del país [...] siendo reconocida -en mayor medida-por las cifras de desplazamientos, asesinatos, secuestros y acciones de guerra que se producen en ellos, y -en menor medida- por las acciones que cuestionan y retan las lógicas del conflicto armado (Garzón, 2008: 184).

Aunque, actualmente, Colombia se encuentra en un proceso de transición tras los acuerdos de paz firmados en La Habana', esto no significa

1 Acuerdo General para la terminación del conflicto y la construcción de una paz estable y duradera (2012). Recuperado de: https://www.mesadeconversaciones.com.co/ sites/default/files/AcuerdoGeneralTerminacion Conflicto.pdf.

Acuerdo final para la terminación del conflicto y la construcción de una paz estable y 
que las secuelas de un conflicto armado de más de cincuenta años (Laverde, 2014) hayan cesado. Por ejemplo, el municipio de Sincelejo, perteneciente al departamento de Sucre, ha sido epicentro receptor de población víctima del conflicto armado en Colombia, específicamente de los Montes de María, siendo una de las ciudades del país que más registra a personas víctimas de desplazamiento forzado (Torres y Vargas, 2009).

Producto del reconocimiento jurídico del estatus de víctimas del conflicto armado, surgió en el país todo un andamiaje normativo que pretende hacer justicia con actos de reparación, restitución, atención psicosocial, reconocimiento de la verdad, justicia y otras medidas de carácter reivindicativo.

Sin embargo, la ineficiencia del Estado para poder ofrecer la atención oportuna y diseñar políticas y estrategias que frenen el aumento de la población desplazada llevó a la Corte Constitucional a pronunciar la Sentencia T-025 de 2004, respecto a lo que denominó "estado de cosas inconstitucional" (Mendoza, 2012).

Cabe destacar que, hoy por hoy, en Colombia, reconoce más de 7 millones de víctimas de desplazamiento forzado en el Registro Único de Víctimas (RUV, 2017), lo que equivale a un $80 \%$ del total de víctimas (Red $\mathrm{Na}$ cional de Información - RNI, 2016). Además, "según reportes de organismos nacionales e internacionales, las mujeres han sido víctimas de múltiples, atroces y sistemáticos crímenes del conflicto armado" (Comisión Nacional de Reparación y Reconciliación, 2013: 305), pues entre 1985 y 2012, el RUV computó que 2.420 .887 de esta población víctima son mujeres, siendo víctimas de varios hechos victimizantes, tales como: desplazamiento forzado, violencia sexual, desaparición forzada, homicidio, minas antipersona, reclutamiento y secuestro (Centro Nacional de Memoria Histórica, 2013).

El impacto de la guerra sobre las mujeres está especialmente marcado por su rol tradicional asignado al cuidado y sostén afectivo del hogar [...] A sus múltiples y pesadas labores domésticas, se suman responsabilidades económicas para sostener sus hogares, además de sobrellevar los impactos dramáticos que les dejaron los hechos violentos vividos (Centro Nacional de Memoria Histórica, 2013: 305).

Una de las condiciones que aun las vuelve más vulnerables es su condición de persona mayor, la cual es definida por la Ley 1279 de 2006 como aquella persona que tiene sesenta (60) años de edad o más, teniendo en

duradera (2016). Recuperado de: https://www.mesadeconversaciones.com.co/sites/ default/files/24-1480106030.11-1480106030.2016nuevo acuerdofinal-1480106030.pdf 
cuenta que por desgaste físico o psicológico pueden considerarla también a partir de los cincuenta y cinco (55) años, pues este grupo poblacional "presenta ciertas características y vulnerabilidades particulares que son diferentes a otros grupos poblaciones, lo que conlleva a estar más afectada por el desplazamiento que otros" (Taylor y Clark, 2010: 3).

Además, "las personas mayores constituyen un grupo frecuentemente invisible en la respuesta institucional al desplazamiento, lo que conduce a que este grupo no logre el goce efectivo de sus derechos" (Taylor y Clark, 2010: 3). "A menudo marginadas antes de que se produjera la crisis, las personas mayores no son incluidas en las evaluaciones sobre las necesidades y los sistemas de registro suelen ignorarlas" (Help Age International y el Observatorio de Desplazamiento Interno, 2011: 76).

Tras lo expresado anteriormente, se crea la necesidad de realizar un estudio que identifique y evalúe las estrategias utilizadas por entidades locales gubernamentales y no gubernamentales dirigidas a la atención de mujeres, mayores de sesenta años, víctimas de desplazamiento forzado en el municipio de Sincelejo, Sucre, con el fin de precisar la correspondencia existente entre estas y lo establecido en la Ley de Víctimas y los criterios de implementación del Programa de Atención Psicosocial y Salud Integral a Víctimas (PAPSIVI, Resolución 1050 del 2016).

\section{PERSONAS MAYORES EN EL MARCO DEL DESPLAZAMIENTO FORZADO}

Primeramente, cabe hacer mención a la Ley 1448 de 2011 "por la cual se dictan medidas de atención, asistencia y reparación integral a las víctimas del conflicto armado interno y se dictan otras disposiciones" (en adelante, Ley de Víctimas), la cual nace como una ley transitoria, vigente hasta el año 2021, la cual recoge una serie de medidas judiciales, administrativas, sociales y económicas, individuales y colectivas, que tienen por objeto hacer posible el goce de los derechos a la verdad, la justicia y la reparación con garantía de no repetición, a las víctimas del conflicto armado en Colombia, de manera que se las reconozca como tal.

Para los efectos de esta ley, se consideran víctimas a todas aquellas personas que:

Individual o colectivamente hayan sufrido un daño a partir del $1^{\circ}$ de enero de 1985 como consecuencia de infracciones al Derecho Internacional Humanitario o de violaciones graves y manifiestas a las normas internacionales de Derechos Humanos, ocurridas con ocasión del conflicto armado interno. También son víctimas el cónyuge, compañero o compañera per- 
manente, parejas del mismo sexo y familiar en primer grado de consanguinidad, primero civil de la víctima directa, cuando a esta se le hubiere dado muerte o estuviere desaparecida. A falta de estas, lo serán los que se encuentren en el segundo grado de consanguinidad ascendente. De la misma forma, se consideran víctimas las personas que hayan sufrido un daño al intervenir para asistir a la víctima en peligro o para prevenir la victimización. La condición de víctima se adquiere con independencia de que se individualice, aprehenda, procese o condene al autor de la conducta punible y de la relación familiar que pueda existir entre el autor y la víctima (Ley de Víctimas, 2011, Artículo 3).

Además, la Ley 387 de 1997 sobre medidas para la prevención del desplazamiento forzado en Colombia reconoce a una persona en esta situación cuando es:

Obligado a abandonar su residencia, sus actividades económicas, sus relaciones interpersonales, su integridad y su libertad debido a que se encuentra amenazado; ya sea por el conflicto armado, tensiones internas en su localidad, violación a sus derechos humanos, al derecho internacional humanitario $u$ otras condiciones en las que se les vea afectada su vida o que puedan afectar en sí, el orden público (art. 1).

Según esta misma Ley, la intervención del Estado para atender a la población desplazada se divide en prevención del desplazamiento forzado, atención humanitaria de emergencia (AHE) y estabilización socioeconómica. Esta última incluye las acciones y medidas del estado para asegurar la sostenibilidad económica y social de la población desplazada que retorne voluntariamente o se asiente en otras zonas, lo que en términos de derechos humanos involucra derechos a la alimentación, salud, educación, vivienda y generación de ingresos.

Haciendo énfasis a las personas mayores en situación de desplazamiento cabe destacar que esta trae consigo una serie de impactos traumáticos: el paso de entornos rurales a urbanos, la ausencia de redes comunitarias y familiares, la carencia de programas y servicios dirigidos a brindarles apoyo, las deficiencias de las políticas públicas, la falta de garantías, etc., lo cual supone más barreras para afrontar la adversidad y una falta de recursos para responder a esta amplia población (Guevara, 2008).

Sin embargo, la Ley 1251 de Protección, Promoción y Defensa de los Derechos de los Adultos Mayores en Colombia pretende proteger, promover, restablecer y defender los derechos de los adultos mayores, orientando políticas que promuevan planes y programas del estado; además de regular el trabajo de las instituciones que le brindan atención a las personas en su vejez, acorde con el artículo 46 de la Constitución Nacional, la Declaración 
de los Derechos Humanos de 1948, Plan de Viena de 1982, Deberes del Hombre de 1948, la Asamblea Mundial de Madrid y los diversos Tratados y Convenios Internacionales suscritos por Colombia.

\section{Respuesta institucional ante personas mayores, víctimas de desplazamiento forzado}

A pesar de lo contemplado anteriormente, cabe destacar que Colombia no aborda suficientemente en su marco actual de políticas y programas la atención a personas mayores (Guevara, 2008), teniendo en cuenta que la Ley 1448 de 2011 establece el principio de enfoque diferencial, el cual reconoce que existen ciertos grupos poblacionales que cuentan con características particulares de atención:

En razón de su edad, género, orientación sexual y situación de discapacidad [...] tales como mujeres, jóvenes, niños y niñas, adultos mayores, personas en situación de discapacidad, campesinos, líderes sociales, miembros de organizaciones sindicales, defensores de Derechos Humanos y víctimas de desplazamiento forzado. (Ley de Víctimas, 2011, Artículo 13).

De ahí, se deberán adoptar criterios diferenciales a la atención y reparación integral a las víctimas (Ley de Víctimas, 2011, art. 159), a través de planes, políticas, programas y estrategias que busquen la inclusión social de esta población (Ley de Víctimas, 2011, art. 173), de manera que respondan a las particularidades y grado de vulnerabilidad de cada uno de estos grupos poblacionales "a fin de contribuir a la eliminación de los esquemas de discriminación y marginación que pudieron ser la causa de los hechos victimizantes" (Ley de Víctimas, 2011, art. 13).

Por ende, se creó el PAPSIVI, el cual contempla la asistencia psicológica y social, la cual guarda estrecha relación con los Derechos Humanos, puesto que además de violarse los derechos de las víctimas y familiares, también, trata de retomar el ejercicio de sus derechos como parte de la atención y el apoyo emocional (Beristain, 2012).

Sin embargo, tras pronunciarse la Sentencia T-025 de 2004, comentada anteriormente, la Corte Constitucional, con el objetivo de subsanar esos aspectos inconstitucionales, puso en marcha desde 2004 dos caminos con el fin de hacer seguimiento a las órdenes de esta sentencia. Por un lado, realizar audiencias públicas en las que, cada cierto tiempo, el gobierno debe dar a conocer el trabajo realizado con el fin de llevarlo a discusión; por otro lado, expedir providencias, conocidas como "autos de seguimiento", con el objetivo de ampliar o aclarar las órdenes al gobierno, solicitar informes, definir indicadores o señales para comparar los avances, etc. 
De este modo, se creó el Auto 092 de 2008, de protección y atención a las mujeres en situación de desplazamiento forzado, en las que se adoptan cuatro medidas. En primer lugar, la creación de 13 programas específicos estatales con perspectiva de género En segundo lugar, establecer dos presunciones constitucionales que amparen a las mujeres desplazadas, dada su situación inmediata de protección, así como la prórroga automática de la ayuda humanitaria de emergencia a favor de las mujeres desplazadas, hasta que puedan alcanzar una autosuficiencia integral, dignidad y estabilidad socioeconómica. En tercer lugar, órdenes individuales de protección específica para seiscientas (600) mujeres desplazadas del país. En cuarto y último lugar, la comunicación al Fiscal General de la Nación de los numerosos relatos de crímenes sexuales cometidos en el marco del conflicto armado interno colombiano.

Es aquí donde se observa que no existe un auto de protección al adulto mayor en situación de desplazamiento. Solamente se hace mención a este grupo poblacional dentro del Auto 006 de 2009, el cual guarda relación con personas desplazadas en situación de discapacidad, tratándose de dos colectivos diferentes $y$, por ende, con distintas necesidades.

De esta manera, a pesar de que en Colombia sí existen avances en la implementación de política pública a población desplazada, existen fallas en la misma, ya que falta decisivamente que se revalúen temas específicos como protección y asistencia (Díaz y Leiva, 2009), no centrándose solamente en atención de emergencia (Contraloría General de la Nación, 2012), dejando en parte relegada el restablecimiento, que es en última instancia, la que posibilita el goce efectivo de derechos.

Persisten deficiencias relacionadas con la focalización y caracterización de la población para su registro, posterior atención, seguimiento de dicha atención y de la inversión efectuada por parte del estado, así como los resultados de la intervención en términos de goce efectivo de derechos (Contraloría General de la Nación, 2012), careciendo de coordinación interinstitucional y de integralidad en el proceso de atención, a pesar de la existencia de comités interinstitucionales que se ocupan de ello (Londoño, 2004).

\section{POLÍTICA PÚBLICA EN EL MARCO DEL DESPLAZAMIENTO FORZADO CON ENFOQUE DIFERENCIAL}

Un estudio realizado por Ibáñez y Velásquez (2008) analizó las posibles causas de la lenta implementación de una política específica para población desplazada y visibilizaron la percepción negativa en cuanto al trato de 
los funcionarios encargados y a los trámites necesarios para demostrar su condición de desplazamiento y obtener cobertura de salud. De hecho, el Registro Único de Personas Desplazadas - RUPD (Mendoza, 2012) expresa que un $30 \%$, es decir, tres de cada diez hogares desplazados, no reciben ayuda del Estado o a nivel internacional porque no están registrados o están tramitando el registro.

Los resultados de los estudios de las entidades del mismo Estado y no gubernamentales muestran el bajo impacto en el cumplimiento de las garantías y los mínimos vitales de las personas desplazadas, junto a la atención diferencial a la población más vulnerable: niños, adultos mayores, personas con discapacidad, grupos étnicos, mujeres en gestación y madres cabeza de familia (Corredor, 2010; citado en Mendoza, 2012).

Centrando este apartado al departamento de Sucre, en Sincelejo, la Alcaldía Municipal (2008) en su "Plan integral único de atención a la población desplazada ubicada en la ciudad de Sincelejo, Departamento de Sucre" buscó actualizar, identificar y reconocer las condiciones específicas del contexto regional, en términos de las necesidades, demandas y oportunidades de la población en situación de desplazamiento para avanzar hacia la realización efectiva y concreción de las estrategias nacionales y superar la brecha entre las decisiones nacionales y acciones territoriales. Se identificó un nivel de atención deficiente, no lográndose una recuperación ni materialización de los derechos de la población desplazada, así como el goce efectivo de los derechos de la misma.

De hecho, una primera toma de datos realizada a entidades como Servicio Nacional de Aprendizaje (SENA)1, Instituto Colombiano de Bienestar Familiar (ICBF)2, Alcaldía Municipal y Unidad de Atención y Reparación Integral a Víctimas del municipio de Sincelejo, Sucre, a través de entrevistas abiertas (comunicaciones personales, julio de 2015) evidenció las brechas existentes en cuanto a la falta de programas, acciones y estrategias que brinden atención integral a este grupo poblacional, haciendo efectivos sus derechos.

Asimismo, tal y como lo expresó la Asociación Mujeres Tejedoras de la Memoria (Sincelejo, Sucre), un grupo conformado mayormente por mujeres mayores de sesenta años, víctimas de desplazamiento y desaparición forza-

1 Institución pública colombiana encargada de dar programas de formación complementaria y titulada.

2 Institución del estado colombiano encargado del desarrollo y la protección de los menores de edad y el de las familias. 
da en varios casos, la ineficiencia del Estado las llevó a conformarse con el objetivo de saber la verdad, velar por la no repetición de los hechos victimizantes que dañaron sus vidas y exigir el goce efectivo de sus derechos, tal y como lo establece la Ley de Víctimas. En este sentido, la presidenta de la Asociación mostraba la insatisfacción que tienen ante la atención brindada por las entidades competentes, sustentando que no tienen apoyo del gobierno en cuanto a asistencia y reparación, expresando lo siguiente: "Ellos no han hecho nada, sino engañarnos, engañarnos totalmente [...] El gobierno en sí nos ha bailado el indio". (R. Paternina, comunicación personal, 21 de febrero de 2016).

\section{MÉTODO}

Con enfoque cualitativo, este estudio pretende primeramente "comprender los fenómenos, explorándolos desde la perspectiva de los participantes en un ambiente natural y con relación con su contexto" (Hernández, 2010: 358).

Asimismo, recoger información sobre las categorías de análisis que se refieren a continuación: Política pública, movilización social y construcción colectiva, planes de acción, planificación estratégica, dinámica operacional, evaluación de resultados y, por último, evaluación de impacto, con el fin de conocer el cumplimiento con lo establecido en la Ley de Víctimas.

La población se compone, principalmente, de nueve (9) entidades gubernamentales y no gubernamentales que atienden a población víctima de desplazamiento forzado en Colombia, específicamente, a mujeres mayores de 60 años, en el municipio de Sincelejo (Sucre, Colombia). Se obtuvo una muestra intencionada de cinco entidades: 4 de ellas gubernamentales y 1 , no gubernamental, previo consentimiento informado.

Para la recolección de la información, se empleó la entrevista semiestructurada como método organizado y flexible que permite interactuar con la persona entrevistada (Álvarez y Jurguenson, 2003). La entrevista, validada por juicio de expertos, está constituida por veintisiete (27) preguntas, distribuidas en las categorías de análisis anteriormente comentadas. Los datos recolectados se analizaron bajo el marco interpretativo de la teoría crítica.

\section{RESULTADOS}

Tras las entrevistas realizadas a cuatro entidades gubernamentales como Secretaria de Agricultura y Desarrollo, Secretaria de Gobierno adscrita a la Gobernación de Sucre, Servicio Nacional de Aprendizaje (SENA) 
y Caja de Compensación Familiar de Sucre (COMFASUCRE) ${ }^{1}$, así como a una entidad no gubernamental, la Diócesis de Sincelejo², se obtuvieron los siguientes resultados.

Tabla 1. Cuadro comparativo de resultados

\begin{tabular}{|c|c|c|}
\hline $\begin{array}{c}\text { ASOCIACIÓN MUJERES } \\
\text { TEJEDORAS DE LA } \\
\text { MEMORIA } \\
\text { (INCONFORMIDADES) }\end{array}$ & $\begin{array}{c}\text { ENTIDADES } \\
\text { GUBERNAMENTALES Y } \\
\text { NO GUBERNAMENTALES } \\
\text { (ESTRATEGIAS } \\
\text { IDENTIFICADAS) }\end{array}$ & $\begin{array}{c}\text { LEY } 1448 \text { DE 2011, LEY DE } \\
\text { VICTIMAS } \\
\text { (MARCO LEGISLATIVO) }\end{array}$ \\
\hline $\begin{array}{l}\text { Las mujeres víctimas expre- } \\
\text { san que: } \\
\text { Ellos no han hecho nada, si } \\
\text { no engañarnos, engañarnos } \\
\text { totalmente. } \\
\text { El gobierno en sí nos ha } \\
\text { bailado el indio. } \\
\text { Para nosotras todo es } \\
\text { importante, pero no se } \\
\text { debe dejar de conocer } \\
\text { nuestro dolor, que lo están } \\
\text { desconociendo tanto, } \\
\text { porque si el gobierno se } \\
\text { hubiera puesto la mano } \\
\text { en el corazón, ya nosotros } \\
\text { tuviéramos reconocimiento } \\
\text { dignamente. } \\
\text { Todo se va en papeles, en } \\
\text { decretos, en documentos. } \\
\text { Necesitamos tener tranqui- } \\
\text { lidad y seguridad. } \\
\text { Queremos verdad, justicia, } \\
\text { reparación digna y no más } \\
\text { repetición. }\end{array}$ & $\begin{array}{l}\text { Servicio Nacional de } \\
\text { Aprendizaje - SENA } \\
\text { - Formación educativa } \\
\text { - Fondo emprender } \\
\text { - Unidad de emprendi- } \\
\text { miento } \\
\text { - Cursos complementa- } \\
\text { rios a población víctima } \\
\text { que incluyen carreras } \\
\text { técnicas, tecnológicas y } \\
\text { especializaciones. } \\
\text { - Enfoque transformador } \\
\text { - Red de apoyo con la } \\
\text { Unidad de Víctimas } \\
\text { - Medidas de satisfacción } \\
\text { - Garantías de no repeti- } \\
\text { ción. }\end{array}$ & $\begin{array}{l}\text { Art. } 51 \text {. Medidas en materia } \\
\text { de educación: } \\
\text { "Dentro de los cupos habilita- } \\
\text { dos y que se habilitaren para } \\
\text { la formación que imparte el } \\
\text { Servicio Nacional de Apren- } \\
\text { dizaje, SENA, se priorizará, } \\
\text { facilitará y garantizará el } \\
\text { acceso a las víctimas de que } \\
\text { trata la presente ley". } \\
\text { Artículo 124. Funciones de } \\
\text { los centros. Desarrollar y } \\
\text { mantener actualizadas las ru- } \\
\text { tas de atención y orientación } \\
\text { a las víctimas. } \\
\text { Art. } 130 \text {. Capacitación y } \\
\text { planes de empleo urbano y } \\
\text { rural: "El Servicio Nacional } \\
\text { de Aprendizaje (Sena) dará } \\
\text { prioridad y facilidad para el } \\
\text { acceso de jóvenes y adultos } \\
\text { víctimas, en los términos de } \\
\text { la presente ley, a sus progra- } \\
\text { mas de formación y capacita- } \\
\text { ción técnica". }\end{array}$ \\
\hline
\end{tabular}

Continúa en la página siguiente...

1 Corporación privada sin ánimo de lucro dedicada a ofrecer servicios de salud, educación, ocio y tiempo libre a los trabajadores afiliados.

2 Jurisdicción eclesiástica de la Iglesia Católica. 


\begin{tabular}{|c|c|c|}
\hline $\begin{array}{c}\text { ASOCIACIÓN MUJERES } \\
\text { TEJEDORAS DE LA } \\
\text { MEMORIA } \\
\text { (INCONFORMIDADES) }\end{array}$ & $\begin{array}{c}\text { ENTIDADES } \\
\text { GUBERNAMENTALES Y } \\
\text { NO GUBERNAMENTALES } \\
\text { (ESTRATEGIAS } \\
\text { IDENTIFICADAS) }\end{array}$ & $\begin{array}{c}\text { LEY } 1448 \text { DE 2011, LEY DE } \\
\text { VICTIMAS } \\
\text { (MARCO LEGISLATIVO) }\end{array}$ \\
\hline $\begin{array}{l}\text { Me da tristeza porque a mí } \\
\text { me toca estar yendo a las } \\
\text { instituciones, entonces que } \\
\text { dicen - no porque ya tú tie- } \\
\text { nes } 10 \text { años, ya tú no tienes } \\
\text { derecho a nada- si el goce } \\
\text { de derechos no ha sido nin- } \\
\text { guno, no trabajas, estás en } \\
\text { peores condiciones, estás } \\
\text { más vieja, porque cada día } \\
\text { que va pasando es un día } \\
\text { de decadencia. } \\
\text { Y no es la plata la que vale } \\
\text { todo, es la estabilidad, } \\
\text { nosotros necesitamos tener } \\
\text { estabilidad y dignidad de } \\
\text { los empleados con uno, } \\
\text { porque a uno le niegan } \\
\text { hasta un servicio médi- } \\
\text { co: va al médico y no te } \\
\text { atienden como es, no le } \\
\text { dan la medicinas, tiene uno } \\
\text { que poner tutela, tiene que } \\
\text { pasar miles, miles conse- } \\
\text { cuencia, entonces jal caído } \\
\text { todo el mundo quiere } \\
\text { caerle encima! }\end{array}$ & $\begin{array}{l}\text { Secretaria de Gobierno } \\
\text { - } \text { Asistencia, atención, } \\
\text { prevención y protección } \\
\text { - } \text { Programa mujer adulta } \\
\text { mayor } \\
\text { - Proyectos productivos } \\
\text { - Programa PAPSIVI } \\
\text { - Fortalecimiento de las } \\
\text { organizaciones y mesas } \\
\text { de participación } \\
\text { - Capacitación para la } \\
\text { normatividad para la } \\
\text { implementación de po- } \\
\text { líticas públicas } \\
\text { Red de apoyo con Coo- } \\
\text { peración Internacional y } \\
\text { alianzas con municipios, } \\
\text { organizaciones, funda- } \\
\text { ciones y convenios. }\end{array}$ & $\begin{array}{l}\text { Artículo 139. Medidas de } \\
\text { satisfacción. El Gobierno } \\
\text { Nacional, a través del Plan } \\
\text { Integral de Reparación } \\
\text { Colectiva para las víctimas, } \\
\text { debe realizar las acciones que } \\
\text { tengan por objeto restablecer } \\
\text { la dignidad de la víctima y } \\
\text { sus miembros, y difundir la } \\
\text { verdad sobre lo sucedido, de } \\
\text { acuerdo con los objetivos de } \\
\text { las entidades que conforman } \\
\text { el Sistema de acuerdo a los } \\
\text { objetivos de las entidades } \\
\text { que conforman el Sistema } \\
\text { Nacional de Atención y Repa- } \\
\text { ración a las Víctimas. }\end{array}$ \\
\hline
\end{tabular}




\begin{tabular}{|c|c|c|}
\hline $\begin{array}{c}\text { ASOCIACIÓN MUJERES } \\
\text { TEJEDORAS DE LA } \\
\text { MEMORIA } \\
\text { (INCONFORMIDADES) }\end{array}$ & $\begin{array}{c}\text { ENTIDADES } \\
\text { GUBERNAMENTALES Y } \\
\text { NO GUBERNAMENTALES } \\
\text { (ESTRATEGIAS } \\
\text { IDENTIFICADAS) }\end{array}$ & $\begin{array}{c}\text { LEY } 1448 \text { DE 2011, LEY DE } \\
\text { VICTIMAS } \\
\text { (MARCO LEGISLATIVO) }\end{array}$ \\
\hline & $\begin{array}{l}\text { No tiene caracterizada la } \\
\text { población víctima, pero } \\
\text { sí existen programas para } \\
\text { generación de ingresos. } \\
\text { No cuentan con estrategias } \\
\text { relacionadas con personas } \\
\text { mayores, sin embargo, } \\
\text { expresan que en el nuevo } \\
\text { plan de desarrollo el } \\
\text { enfoque diferencial y de } \\
\text { género se contempla en } \\
\text { sus programas. } \\
\text { No brinda información de } \\
\text { cómo mejorar la atención } \\
\text { a la población objeto de } \\
\text { estudio. } \\
\text { Presentan quejas fre- } \\
\text { cuentes por demora en la } \\
\text { atención, sobre todo, para } \\
\text { el pago de la ayuda huma- } \\
\text { nitaria y por el poco apoyo } \\
\text { a los espacios de partici- } \\
\text { pación de esta población, } \\
\text { todo esto debido a falta de } \\
\text { recursos. }\end{array}$ & $\begin{array}{l}\text { Artículo 163. Órganos de di- } \\
\text { rección, coordinación y eje- } \\
\text { cución de la política pública } \\
\text { en materia de asistencia, } \\
\text { atención y reparación a las } \\
\text { víctimas: "Para la formulación } \\
\text { y adopción de las políticas, } \\
\text { planes generales, programas } \\
\text { y proyectos para la asistencia, } \\
\text { atención y reparación a las } \\
\text { víctimas de las violaciones } \\
\text { contempladas en el artículo } \\
3^{\circ} \text { de la presente Ley, reinte- } \\
\text { gración económica, se creará } \\
\text { una institución de primer } \\
\text { nivel de la administración } \\
\text { Pública, del sector central, de } \\
\text { la Rama Ejecutiva del orden } \\
\text { nacional". } \\
\text { Artículo } 173 \text {. Coordinación } \\
\text { de acciones con las entida- } \\
\text { des que conforman el Siste- } \\
\text { ma Nacional de Atención y } \\
\text { Reparación a Víctimas. }\end{array}$ \\
\hline & $\begin{array}{l}\text { Secretaria de Desarrollo y } \\
\text { Agricultura } \\
\text { - Ganadería (mejoramien- } \\
\text { to ganadero) } \\
\text { - Agricultura (con cultivos } \\
\text { tradicionales y comer- } \\
\text { ciales) } \\
\text { - Micro empresariales (ar- } \\
\text { tesanía, bisutería, belle- } \\
\text { za) } \\
\text { Establecer cultivo para } \\
\text { animales }\end{array}$ & $\begin{array}{l}\text { Artículo 206. Desarrollo } \\
\text { rural: "El Gobierno Nacional, } \\
\text { a través del Ministerio de } \\
\text { Agricultura y Desarrollo Rural, } \\
\text { deberá presentar la iniciativa } \\
\text { que regule el desarrollo rural } \\
\text { del país, donde se prioricen } \\
\text { las víctimas de despojo y } \\
\text { abandono forzado, en el } \\
\text { acceso a créditos, asistencia } \\
\text { técnica, adecuación predial, } \\
\text { programas de comerciali- } \\
\text { zación de productos, entre } \\
\text { otros, que contribuyan a la } \\
\text { reparación de las víctimas". }\end{array}$ \\
\hline
\end{tabular}




\begin{tabular}{|c|c|c|}
\hline $\begin{array}{c}\text { ASOCIACIÓN MUJERES } \\
\text { TEJEDORAS DE LA } \\
\text { MEMORIA } \\
\text { (INCONFORMIDADES) }\end{array}$ & $\begin{array}{c}\text { ENTIDADES } \\
\text { GUBERNAMENTALES Y } \\
\text { NO GUBERNAMENTALES } \\
\text { (ESTRATEGIAS } \\
\text { IDENTIFICADAS) }\end{array}$ & $\begin{array}{c}\text { LEY } 1448 \text { DE 2011, LEY DE } \\
\text { VICTIMAS } \\
\text { (MARCO LEGISLATIVO) }\end{array}$ \\
\hline & $\begin{array}{l}\text { Población general benefi- } \\
\text { ciaria. } \\
\text { No aplican enfoque dife- } \\
\text { rencial. } \\
\text { No cuentan con estrategias } \\
\text { relacionadas con personas } \\
\text { mayores. } \\
\text { No brinda información de } \\
\text { cómo mejorar la atención } \\
\text { a la población objeto de } \\
\text { estudio. }\end{array}$ & \\
\hline & $\begin{array}{l}\text { Caja de Compensación } \\
\text { Familiar de Sucre - COM- } \\
\text { FASUCRE } \\
\text { - Caracterización para } \\
\text { programa de capacita- } \\
\text { ción } \\
\text { - Vivienda } \\
\text { - Empleabilidad } \\
\text { - Bienestar } \\
\text { - Orientación laboral } \\
\text { Hay programas para perso- } \\
\text { nas mayores, sin embargo, } \\
\text { no se brindó más informa- } \\
\text { ción al respecto. } \\
\text { Propuesta de ruta de } \\
\text { empleabilidad a población } \\
\text { víctima. } \\
\text { Garantías de no repetición. } \\
\text { No brinda información de } \\
\text { cómo mejorar la atención } \\
\text { a la población objeto de } \\
\text { estudio. }\end{array}$ & $\begin{array}{l}\text { Artículo 123. Medidas de } \\
\text { restitución en materia de vi- } \\
\text { vienda: "La población víctima } \\
\text { del desplazamiento forzado, } \\
\text { accederá a los programas y } \\
\text { proyectos diseñados por el } \\
\text { Gobierno, privilegiando a la } \\
\text { población mujeres cabeza } \\
\text { de familia desplazadas, los } \\
\text { adultos mayores desplazados } \\
\text { y la población discapacitada } \\
\text { desplazada". } \\
\text { Artículo 130. Capacitación } \\
\text { y planes de empleo urbano } \\
\text { y rural: "A través del Minis- } \\
\text { terio de la Protección Social } \\
\text { y el Servicio Nacional de } \\
\text { Aprendizaje (Sena), diseñará } \\
\text { programas y proyectos espe- } \\
\text { ciales para la generación de } \\
\text { empleo rural y urbano con el } \\
\text { fin de apoyar el auto sosteni- } \\
\text { miento de las víctimas, el cual } \\
\text { se implementará a través del } \\
\text { Plan Nacional para la Aten- } \\
\text { ción y Reparación Integral a } \\
\text { las Víctimas". }\end{array}$ \\
\hline
\end{tabular}




\begin{tabular}{|c|c|c|}
\hline $\begin{array}{c}\text { ASOCIACIÓN MUJERES } \\
\text { TEJEDORAS DE LA } \\
\text { MEMORIA } \\
\text { (INCONFORMIDADES) }\end{array}$ & $\begin{array}{c}\text { ENTIDADES } \\
\text { GUBERNAMENTALES Y } \\
\text { NO GUBERNAMENTALES } \\
\text { (ESTRATEGIAS } \\
\text { IDENTIFICADAS) }\end{array}$ & $\begin{array}{c}\text { LEY } 1448 \text { DE 2011, LEY DE } \\
\text { VICTIMAS } \\
\text { (MARCO LEGISLATIVO) }\end{array}$ \\
\hline & & $\begin{array}{l}\text { Artículo } 165 \text {. Funciones del } \\
\text { comité ejecutivo para la } \\
\text { atención y reparación a las } \\
\text { víctimas: "Las entidades del } \\
\text { Sistema Nacional de Atención } \\
\text { y Reparación a las Víctimas } \\
\text { garantizaran la consecución } \\
\text { de recursos presupuestales, } \\
\text { y gestionar la consecución } \\
\text { de los recursos financieros } \\
\text { provenientes de fuentes de } \\
\text { financiación diferentes al } \\
\text { Presupuesto General de la } \\
\text { Nación, para garantizar la } \\
\text { adecuada y oportuna presta- } \\
\text { ción de los servicios". }\end{array}$ \\
\hline & $\begin{array}{l}\text { Diócesis } \\
\text { - Proyectos dirigidos a } \\
\text { población vulnerable y } \\
\text { víctimas. } \\
\text { - } \text { Atención psicosocial } \\
\text { - Proyecto de vida } \\
\text { - Reconocimiento como } \\
\text { mujeres } \\
\text { - Reconocimiento de sus } \\
\text { - } \text { derechos } \\
\text { Promoción en la partici- } \\
\text { - } \text { Pación de la mujer } \\
\text { - } \text { riales } \\
\text { - } \text { tumaciones empresa- } \\
\text { - Enfoquad la espiri- } \\
\text { - Redes de apoyo }\end{array}$ & $\begin{array}{l}\text { Artículo 124. Funciones de } \\
\text { los centros. Desarrollar y } \\
\text { mantener actualizadas las } \\
\text { rutas de atención y orienta- } \\
\text { ción a las víctimas. } \\
\text { Art. 137. Programa de } \\
\text { atención psicosocial y salud } \\
\text { integral a las víctimas: "El } \\
\text { Programa de Atención Psico- } \\
\text { social y Salud Integral a Vícti- } \\
\text { mas, el cual se implementará } \\
\text { a través del Plan Nacional } \\
\text { para la Atención y Repara- } \\
\text { ción Integral a las Víctimas, } \\
\text { comenzando en las zonas con } \\
\text { mayor presencia de víctimas". }\end{array}$ \\
\hline
\end{tabular}

Continúa en la página siguiente... 


\begin{tabular}{|c|c|c|}
\hline $\begin{array}{c}\text { ASOCIACIÓN MUJERES } \\
\text { TEJEDORAS DE LA } \\
\text { MEMORIA } \\
\text { (INCONFORMIDADES) }\end{array}$ & $\begin{array}{c}\text { ENTIDADES } \\
\text { GUBERNAMENTALES Y } \\
\text { NO GUBERNAMENTALES } \\
\text { (ESTRATEGIAS } \\
\text { IDENTIFICADAS) }\end{array}$ & $\begin{array}{c}\text { LEY } 1448 \text { DE 2011, LEY DE } \\
\text { VICTIMAS } \\
\text { (MARCO LEGISLATIVO) }\end{array}$ \\
\hline & $\begin{array}{l}\text { No cuentan con estrategias } \\
\text { relacionadas con personas } \\
\text { mayores. } \\
\text { Garantías de no repetición. } \\
\text { Evaluación de resultados } \\
\text { según población benefi- } \\
\text { ciaria. }\end{array}$ & $\begin{array}{l}\text { Artículo 138. De la estructu- } \\
\text { ra, funciones, operatividad } \\
\text { del programa de atención } \\
\text { psicosocial y salud integral } \\
\text { a las víctimas: "El gobierno } \\
\text { nacional deberá establecer la } \\
\text { articulación con las entidades } \\
\text { territoriales de acuerdo a } \\
\text { los artículos } 172 \text { y } 173 \text { de la } \\
\text { presente Ley, para su cum- } \\
\text { plimiento en el nivel territo- } \\
\text { rial, especialmente, para el } \\
\text { desarrollo de la estrategia del } \\
\text { Modelo Único de Atención } \\
\text { Integral a Víctimas". }\end{array}$ \\
\hline
\end{tabular}

Fuente: Elaboración propia

\section{CONCLUSIONES}

El objetivo de este estudio fue evaluar las estrategias socioeconómicas implementadas por cinco (5) entidades locales gubernamentales y no gubernamentales dirigidas a la mujer adulta mayor, víctima de desplazamiento forzado, en el municipio de Sincelejo, Sucre, Colombia, con el fin de conocer la labor que estas entidades están llevando a cabo para mejorar la calidad de vida de esta población. Asimismo, evaluar cómo se ejecutan dichas estrategias de acuerdo a lo establecido por la Ley de Víctimas, legislación que respalda la protección y el restablecimiento de los derechos de las víctimas de desplazamiento forzado en Colombia.

Específicamente y según los resultados de este estudio, se señala el SENA, mediante su plan de acción, el cual pretende que la población desplazada tenga acceso a los programas de formación, con el fin de que estas personas logren desarrollar sus capacidades y habilidades para un mejor desarrollo social, garantizándoles así una mejor calidad de vida. Además, mejorar la calidad de vida a través de una idea de negocio para generar ingresos. Todo ello, bajo la premisa del enfoque transformador que recoge la Ley.

Sin embargo, cabe recordar que se está hablando de personas mayores que no tienen las necesidades básicas cubiertas, tal y como lo expresan 
las Mujeres Tejedoras de la Memoria, de manera que este tipo de servicios no tienen en cuenta a esta población, ni las necesidades y particularidades de esta.

Tanto la Secretaria de Gobierno como la Secretaria de Desarrollo y Agricultura se orientan, principalmente, a financiar actividades productivas, es decir, aquellas relacionadas con el sector rural y agrícola. Se coordinan con la Unidad de Víctimas en caso de trabajar con población víctima. En cuanto a las personas mayores, ambas entidades no tienen caracterizada a este grupo poblacional, no aplicándose el enfoque diferencial. Tampoco brindan información de cómo mejorar la atención de esta población, lo cual conlleva a su invisibilización y aislamiento.

Por otro lado, Comfasucre no contempla dentro su plan estratégico, programas que vayan dirigidos a población víctima, quizás porque esta población se encuentra con dificultades a la hora de laborar. En cuanto a las personas mayores, no brindaron información sobre cuáles son los programas existentes para este grupo poblacional.

Por último, la Diócesis de Sincelejo realiza proyectos dirigidos a población vulnerable y víctimas, sin embargo, no cuentan con estrategias relacionadas con personas mayores. Tanto la Diócesis como el Sena buscan como propósito principal el enfoque transformador estipulado en el artículo $5^{\circ}$ de la Ley, como estrategia para mejorar su atención, de manera que la persona reconozca sus derechos, conozca su participación en la sociedad y tenga la capacidad para poder solventar sus necesidades, generando sus propios ingresos. El resto de entidades no expresa cómo mejorar la atención hacia esta población.

Con respecto a la motivación institucional, las entidades como Sena, Comfasucre y Diócesis cumplen con lo establecido en la Ley según en el artículo 149 de "garantías de no repetición", en el que el Estado debe adoptar programas y proyectos de no repetición que incluyan acciones afirmativas, económicas y políticas que cubran las necesidades de la población y que estas no vuelvan a ser objetos de violaciones de sus derechos humanos y derecho internacional humanitario.

Ninguna entidad brinda información acerca del presupuesto destinado a población la población víctima.

De manera general, cabe hacer énfasis que ninguna de las entidades contempla la atención a personas mayores, tampoco en situación de desplazamiento forzado y según su género, no dándose cumplimiento al enfoque diferencial estipulado por la Ley de Víctimas, de manera que se obvia 
la premisa de que existen ciertos grupos poblacionales que cuentan con características particulares de atención. Por lo tanto, no se están adoptando criterios diferenciales a la atención de víctimas, sino que esta población se encuentra sumergida dentro de la población en general, no protegiendo, promoviendo, restableciendo ni defendiendo los derechos de las personas mayores, tal y como señala la Ley 1251.

Estas entidades tienen deficiencias relacionadas con la focalización y caracterización de la población para su registro, posterior atención, seguimiento de dicha atención y de la inversión efectuada por parte del estado, así como los resultados de la intervención en términos de goce efectivo de derechos. Sin embargo, la Ley 387 de 1997 apunta a acciones y medidas del estado para asegurar la sostenibilidad económica y social de la población desplazada, lo que en términos de derechos humanos involucra derechos a la alimentación, salud, educación, vivienda y generación de ingresos, lo que en población de personas mayores no se evidencia para una estabilización socioeconómica óptima.

De este modo, el hecho de que no se aborde suficientemente en el marco actual de políticas y programas la atención a personas mayores hace que estos pierdan relevancia. Prueba de ello, es no contar con un auto de seguimiento para este grupo poblacional en situación de desplazamiento.

Ello conlleva a que se identifique en estas entidades invisibilidad de la población de personas mayores, de modo que existen falencias en las políticas públicas de atención integral e inclusión a la población víctima, específicamente, en mujeres adultas mayores, dado que no hay un cumplimento efectivo que garantice el goce de los derechos de las víctimas.

A pesar de que hay proyectos y programas que trabajen en beneficio de la población víctima, no hay una caracterización que sopese el trabajo realizado, de modo que todo aquello que no deja evidencia es como si no hubiera existido nunca. Además, las entidades no contemplan acciones que tengan en cuenta la población objeto de estudio, no existiendo inclusión al respecto, no cumpliéndose el enfoque diferencial plasmado en el artículo $3^{\circ}$ y $13^{\circ}$ de la Ley de Víctimas.

Con base a lo mencionado anteriormente, es de gran importancia profundizar en la aplicación de la Ley 1448 del 2011 en cada una de las entidades, siendo necesario emprender un proceso en las revisiones de las funciones que atribuye el estado, con el objetivo de mejorar en los procesos de asistencia, atención, reparación integral e inclusión de la población víctima.

Por ende, se recomiendan las siguientes acciones: a) Ejecutar accio- 
nes enfocadas a la profundización de la Ley 1448 de 2011 en las distintas entidades encargadas de la atención a víctimas; b) Estudiar a fondo las necesidades e intereses que tiene la población víctima y mayor de sesenta años para evitar la creación de políticas públicas que no vayan a cubrir dichas necesidades e intereses de manera integral; c) Realizar seguimiento a los programas, proyectos, planes y estrategias en beneficio a la población objeto de estudio para su efectiva ejecución.

\section{REFERENCIAS BIBLIOGRÁFICAS}

ACNUR (2014). Mundo en Guerra. Desplazamiento forzado. Tendencias globales 2014. Recuperado de: http://www.acnur.org/t3/fileadmin/scripts/doc.php?file=t3/fileadmin/Documentos/Publicaciones/2015/10072

Alcaldía Municipal Sincelejo, Sucre (2008). Plan integral único de atención a la población desplazada ubicada en la ciudad de Sincelejo, Departamento de Sucre, Colombia. Sucre, Colombia: Autor. Recuperado de: http://sincelejo-sucre.gov.co/apc-aa-files/37366363613361636164636236313832/Plan_Integral_Unico_de_Desplazados.pdf

Álvarez, J. y Jurguenson, G. (2003). Como hacer investigación cualitativa: fundamentos y metodología. México D.F.; México: Paidós Mexicana S.A.

Beristain, C. (2012). Acompañar los procesos con las víctimas. Fondo de justicia transicional. Edición No. 1. Colombia: PNUD.

Centro Nacional de Memoria Histórica (2013). Informe general. Cap. IV. Los impactos y los daños causados por el conflicto armado en Colombia. Recuperado de http://centrodememoriahistorica.gov.co/descargas/informes2013/bastaYa/capitulos/basta-ya-cap4_258-327.pdf

Comisión Nacional de Reparación y Reconciliación (Colombia). Área de Memoria Histórica. (2013) ¡Basta ya! Colombia: Memorias de guerra y dignidad. Centro Nacional de Memoria Histórica.

Congreso de Colombia. (10 de junio de 2011). Ley de víctimas y restitución de tierras. [Ley 1448 de 2011]. DO: 41.101

Congreso de Colombia. (18 de julio de 1997). Medidas para la prevención del desplazamiento forzado [Ley 387 de 1997]. DO: 43.091.

Congreso de Colombia. (27 de noviembre de 2008) Artículo 1 [Título I]. Por la cual se dictan normas tendientes a la protección, promoción y defensa de los derechos humanos del adulto mayor [Ley 1251 de 2008]. DO: 47.186. / Recuperado de: http://www.icbf.gov.co/cargues/avance/docs/ley_1251_2008.htm

Congreso de Colombia. Sentencia ${ }^{\circ}$ T-025 de 2004, para la atención y protección a población desplazada.

Contraloría General de la Nación (2012). Informe sectorial: Atención a población en situación de desplazamiento en el distrito capital. Bogotá, Colombia: Autor. Recuperado de: http://www.contraloriabogota.gov.co/intranet/contenido/ informes/Sectoriales/Subdireccion\%20de\%20evaluacion\%20sectorial/Atencion\%20a\%20poblacion\%20en\%20situacion\%20de\%20desplazamiento.pdf

Díaz, V. y Leiva, P. (2009). La gente de nadie: Desplazamiento forzado. (Trabajo de 
Estrategias socioeconómicas de inclusión de entidades locales dirigidas a personas mayores (mujeres), víctimas de desplazamiento forzado

grado). Universidad del Rosario, Colombia. Recuperado: http://repository. urosario.edu.co/bitstream/handle/10336/1256/1019005462.pdf?sequen$\mathrm{ce}=1$

Garzón, M. A. (2008). Retando las geografías de terror: estrategias culturales para la construcción del lugar. Nómadas, 28, 183-193. Recuperado de: http://www. scielo.org.co/pdf/noma/n28/n28a17

Guevara, R. D. (2008). Violencia y desplazamiento: caracterización de las mujeres desplazadas jefas de hogar del municipio de Florida, Valle del Cauca. Reflexión Política, 10(20), 154-173.

HelpAge International y el Observatorio de Desplazamiento Interno (2011). La generación desatendida. El impacto del desplazamiento en la gente mayor. New York: Piero Calvi-Parisett.

Hernández, R.; Fernández, C. y Baptista, M. P. (2010). Metodología de la investigación. $5^{a}$ edición. México: McGraw Hill.

Ibáñez, A. M. y Velásquez, A. (2008). La política pública para atender a la población desplazada: ¿Cuáles deben ser las funciones de las autoridades locales? Washington, DC: Institución Brookings, Universidad de Berna. http://www. brookings.edu/ /media/research/files/reports/2008/12/03-colombia-ibanez/1203_colombia_ibanez_spa.pdf

Ibáñez, A. M. y Velásquez, A. (2008). El impacto del desplazamiento forzoso en Colombia: condiciones socioeconómicas de la población desplazada, vinculación a los mercados laborales y políticas públicas. Chile: División de Desarrollo Social. Recuperado de: http://www.cepal.org/publicaciones/ xml/2/35022/sps145-Desplazamiento-Colombia.pdf

Laverde, J. (2014). Las Farc: 50 años de conflicto. Revista el espectador. Recuperado de: http://www.elespectador.com/noticias/paz/farc-50-anos-de-conflicto-armado-articulo-494175

Londoño, B. (2004). Bogotá: una ciudad receptora de migrantes y desplazados con graves carencias en materia de recursos y de institucionalidad para garantizarles sus derechos. Revista Estudios Socio-Jurídicos, 6(1), 353-375.

Mendoza, A. M. (2012). El desplazamiento forzado en Colombia y la intervención del estado. Revista de Economía Institucional, 14(26), 169-202. Recuperado de: http://www.economiainstitucional.com/pdf/no26/amendoza.pdf

Ministerio de Salud (2012). Programa de atención psicosocial y salud integral a víctimas - PAPSIVI. Recuperado de https://www.minsalud.gov.co/proteccionsocial/Paginas/Victimas_PAPSIVI.aspx

Red Nacional de Información - RNI (2016). Víctimas registradas históricamente. Fecha de corte: 12 mayo. Bogotá, Colombia: Registro Único de Víctimas. Recuperado de http://rni.unidadvictimas.gov.co/RUV

República de Colombia (2016). Acuerdo final para la terminación del conflicto y la construcción de una paz estable y duradera (24-11-2016). Recuperado de https://www.mesadeconversaciones.com.co/sites/default/files/24-14801060 30.11-1480106030.2016nuevoacuerdofinal-1480106030.pdf 
Marta Sahagún-Navarro Leandra Orozco-Tous Martha Vergara-Garay Silvia García-Arias

Taylor, S. y Clark, F. (2010). Obligados a cambiar de horizontes: Desplazamiento forzado, un enfoque diferencial para las personas adultas mayores en Cali, Colombia. Colombia: HelpAge International.

Torres, C. A., y Vargas, J. E. (2009). Vivienda para población desplazada en Colombia: recomendaciones para la política pública y exigibilidad del derecho. Revista INVI, 24(66), 17-86. https://dx.doi.org/10.4067/S0718-83582009000200002 